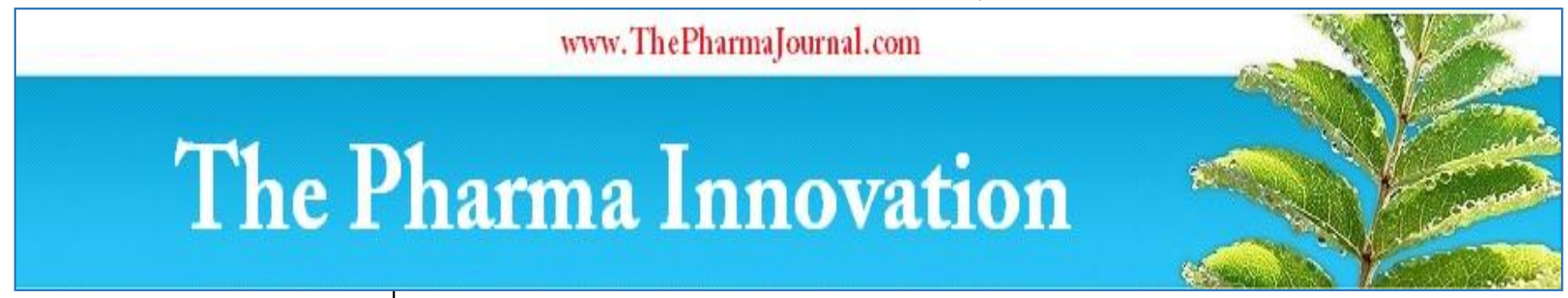

ISSN (E): 2277 - 7695

ISSN (P): 2349-8242

NAAS Rating: $\mathbf{5 . 0 3}$

TPI 2020; 9(6): 412-424

(c) 2020 TPI

www.thepharmajournal.com

Received: 17-04-2020

Accepted: 22-05-2020

\section{Ankit Kumar}

Department of Pharmacy, R.K. Group of Institutions, Naini,

Allahabad, Uttar Pradesh, India

Amita Verma

Bioorganic and Medicinal

Chemistry Research Laboratory,

Department of Pharmaceutical

Sciences, Sam Higginbottom

University of Agriculture,

Technology and Sciences,

Allahabad, Uttar Pradesh, India

\section{Corresponding Author:}

\section{Amita Verm}

Bioorganic and Medicinal

Chemistry Research Laboratory, Department of Pharmaceutical Sciences, Sam Higginbottom University of Agriculture,

Technology and Sciences,

Allahabad, Uttar Pradesh, India

\section{Natural bioactive products with antioxidant properties useful in neurodegenerative diseases}

\author{
Ankit Kumar and Amita Verma
}

DOI: https://doi.org/10.22271/tpi.2020.v9.i6f.4803

\section{Abstract}

Oxidative stress is one of the principal causes behind the progression of several neurodegenerative diseases such as Alzheimer's disease, Parkinson's disease, Huntington's disease, neurosclerosis and others. Reactive oxygen species and reactive nitrogen species are the major reduced moieties produced during the cellular oxidative stress which are responsible for the neural damage and death. Therefore, the compounds or group of compounds which are capable of limiting the concentration of these reduced form of oxygen commonly known as antioxidants can be the promising elements in controlling or recovering the neurodegenerative diseases. This article deals with various naturally active antioxidants which have been evidenced in the management of the neurodegenerative diseases. In this context, we have concluded the role of polyphenols, alkaloids, vitamins, terpenoids and several other bioactive compounds in the preventive and curative measures of different neurological disorders.

Keywords: Neurodegenerative disease, polyphenols, Alzheimer's disease, Parkinson's disease, vitamins

\section{Introduction}

The neurodegenerative diseases are the major group of pathophysiological conditions which include either alterations in the neuronal structures or stiffening of the neurons (Neurosclerosis) or the loss of the neurons itself. These conditions are generally characterized either due to accumulation of protein, or inflammation or oxidative stress in the CNS which lead to cause various behavioral changes such as cognition impairment, motor dysfunction, depression etc ${ }^{[1]}$.

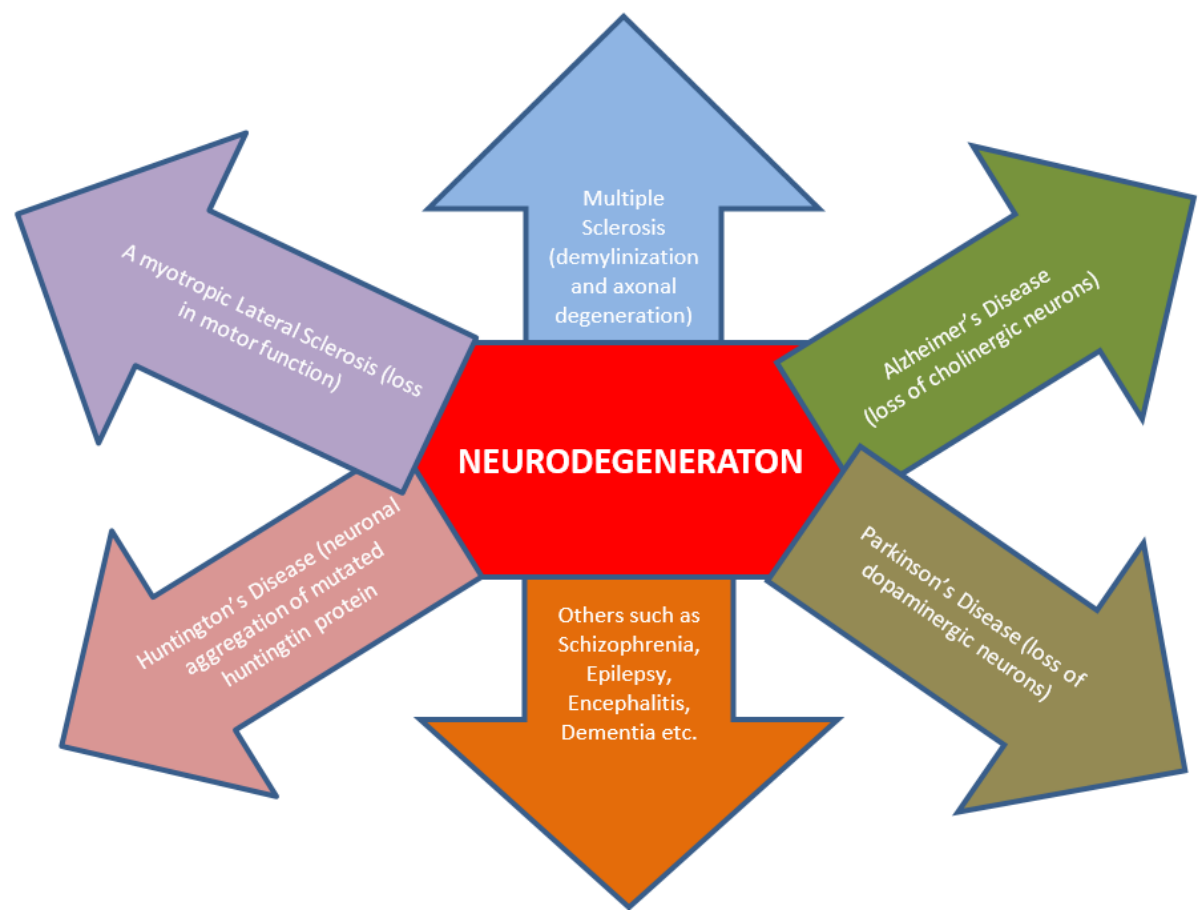

Fig 1: Major Neurodegeneration with possible etiology 
Sometimes, damage to the BBB (Blood Brain Barrier), insufficient synthesis or depletion of the neurotransmitters due to enhance activity of the enzymes, autophagia, etc. may also be the etiology behind the neurodegeneration. The most commonly known diseases due to improper generation and progression of the neurons are Alzheimer's Disease (AD), Parkinson's Disease (PD), Huntington's Disease (HD), amyotrophic lateral sclerosis (ALS), multiple sclerosis (MS) etc. (refer fig. 1) Neurodegenerative diseases cause a substantial burden over the globe because of communicable conditions such as meningitis \& Japanese encephalitis as well as non-communicable conditions such as AD, PD, HD, cerebrovascular diseases etc. ${ }^{[2]}$. The various substrates which are taken by the body to generate energy are being oxidized by using molecular oxygen and in the meanwhile, these oxygen molecules get converted into reduced form of oxygen (Reactive Oxygen Species or ROS) such as peroxide and superoxide radicals. In various circumstances, superoxide radicals react with nitric oxide (NO) to produce peroxynitrite radicals $\left(\mathrm{OONO}^{-}\right)$, commonly called as Reactive Nitrogen Species (RNS) ${ }^{[3]}$. ROS and RNS are to be considered as the possible factors of neurodegeneration and can also be formed under various stressed conditions such as

a) Continuous direct contact with UV radiations

b) Metal catalyzed reaction in the body

c) Product produced by neutrophils and macrophages during inflammation

d) Products produced during electron transport chain reaction in mitochondria, etc. ${ }^{[4]}$.

Apart from this, it has been surveyed that poor life-style is one of the major factor behind the generation of such oxidative stress and progression of various neurological disorders ${ }^{[5]}$. These reduced form of oxygen acts as a double edged sword in the biological system. They behave as the soldiers and encounter all the infectious agents when present at lower concentration in the body. But these can cause stress in the activation of neuron factor-kappa B in the brain even cause damage to various organs of the body when present at higher concentration ${ }^{[6]}$. Their concentration and action are enzymatically or non-enzymatically controlled by the special defense mechanism of the various cells present in the different organs of the body ${ }^{[7]}$. Superoxide dismutase and glutathione peroxidase are the few enzymes available on the either sides of the mitochondrial membrane (major free radical site) which scavenge the aggravate number of free radicals. Among the various non-enzymatic antioxidant (refer Table 1), vitamin C (8) \& vitamin E (16) play the most important role but in different types of condition ${ }^{[8]}$. For example, vitamin $\mathrm{C}$ combines with superoxide in the aqueous environment where as vitamin E combines effectively with the same but in the non-aqueous phase. On contrary, $\alpha$-lipoic acid is a natural reducing agent which can act in both types of situation. Fruits like pomegranate, apricot etc. vegetables like tomato, potato, carrot etc., nuts like walnut, peanut etc. \& beverages such red wine, green tea are certain substance which are essential to maintain the redox system in the body or specifically brain ${ }^{[9,10]}$. Therefore, the antioxidant pools available naturally in the physiological system often requires some nourishments and support in order to encounter the produced free radicals which can be done by the above mentioned items. There are various species of plants and even microorganisms which are rich in the compounds accessible to reduce the blackballed concentration of free radicals and balance the cellular redox of the system. Flavonoids and other polyphenols ${ }^{[11]}$, terpenoids, alkaloids, are the secondary metabolites which are helpful in the management of the CNS diseases. For example,

1. Luteolin, which is a flavonoid, has been reported its vital function in the treatment of multiple CNS disorders such as inhibition of mast cell degranulation, protection against mitochondrial damage, activation and proliferation of microglia etc.

2. Vitamin supplementation has been informed in the modulation of clinical symptoms of Parkinson's disease.

3. Borneol has been shown its efficacy in the amelioration of BBB permeability, thus acting as neuroprotector ${ }^{[12]}$. Similarly, water habitants have been also shown some tremendous effects in the modulation of neurodegenerative diseases.

4. Onchidal which is an acetate ester isolated from mollusc Onchidella binneyi, has been shown its ability to inhibit acetylcholine esterase enzyme, therefore it can be helpful in the management of $\mathrm{AD}{ }^{[13]}$. In this section, we will discuss about various natural compounds and their derivatives responsible for the amelioration in the severe CNS disorders.

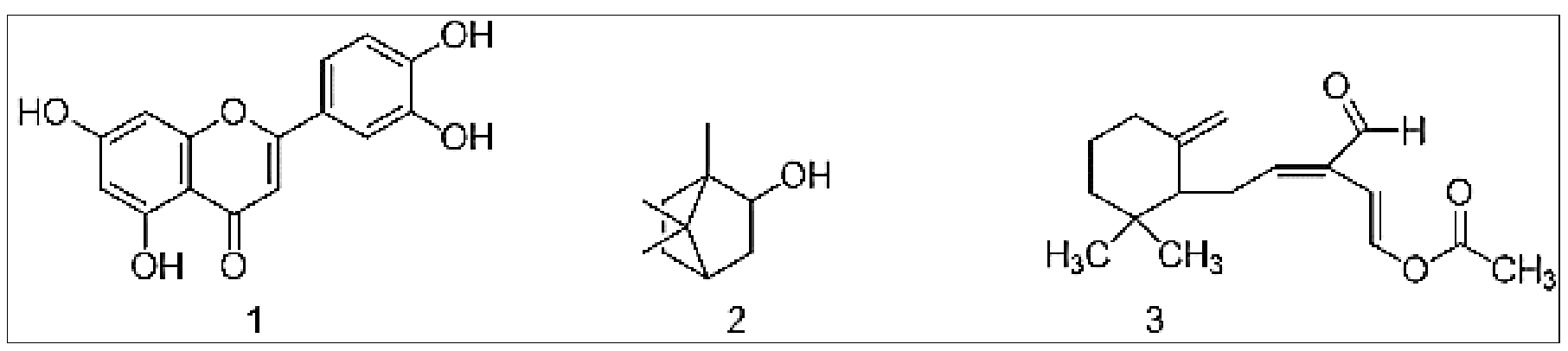

Table 1: Natural exogenous antioxidants ${ }^{[14]}$

\begin{tabular}{|c|c|c|c|c|c|c|}
\hline \multicolumn{7}{|c|}{ Natural exogenous sources of Antioxidants } \\
\hline \multicolumn{2}{|c|}{ Polyphenols } & Alkaloids & Vitamins & Terpenoids & Others & \\
\hline $\begin{array}{c}\text { Flavonoids } \\
\text { Flavonols, Flavanones, } \\
\text { Flavones, Isoflavanoids, } \\
\text { Anthocyanidins }\end{array}$ & $\begin{array}{l}\text { Polyphenolic acid } \\
\text { Ferulic acid, p- } \\
\text { Coumaric acid, Gallic } \\
\text { acid, Ellagic acid }\end{array}$ & $\begin{array}{l}\text { Vindolicine, } \\
\text { Boldine, } \\
\text { Tetrandine, } \\
\text { Caffeine }\end{array}$ & $\begin{array}{l}\text { Vitamin A } \\
\text { Vitamin C } \\
\text { Vitamin E }\end{array}$ & $\begin{array}{l}\text { Carotenoids, } \\
\text { Lycopene }\end{array}$ & \begin{tabular}{|c|} 
Proteins \\
Albumin, Ceruloplasmin, \\
Hepatoglobin, \\
Lectoferrin, etc.
\end{tabular} & $\begin{array}{l}\text { Non proteins } \\
\text { (Bilirubin, } \\
\text { Ubiquinol, Uric } \\
\text { acid) }\end{array}$ \\
\hline
\end{tabular}


Class of Natural Antioxidants useful in the management as well as treatment of various CNS disorders

1. Polyphenols: Neurodegenerative problems are being majorly associated with the aging effects which gives an idea to reduce the oxidative stress responsible for the aging as well as to treat mentioned malady. For such purpose, polyphenolic compounds produce very promising effect by reducing the various free radicals resulted from the oxidative stress. Flavonoids such as anthocyanins, flavonols, flavones, flavanones, isoflavonoids, flavanols come under this class of compounds where as lignans, stilbenes, phenolic acids are the examples of non-flavonoid polyphenols. These are considered as broad spectrum compounds since they act through multiple mechanisms in order to prevent and manage various neurodegenerative problems. The possible ways through which polyphenols can act are as follows:-

a) By acting through antioxidant pathways

b) By modulating the various neurotransmitters and enzymes such as acetylcholine esterase

c) By acting on the amyloidogenic pathways

d) By interacting with signalling pathways

e) By inhibiting NMDA (N-methyl-d-aspartate) neurotoxicity ${ }^{[15]}$, but our major focus will be on its first above mentioned mechanism only.

As we have already discussed various categories of polyphenols, it has been found that the antioxidant action of different types of polyphenols exist through different mechanisms in different types of cell lines studied. The reported pathways through which polyphenols reveal its antioxidant properties are follows:-

i) HIF-1 (Hypoxia Inducible Factor-1 alpha) Pathways- This pathway is responsible for the transduction and expression of the genes responsible for inducing the mediatory survival condition for the cells. Two subunits ,i.e. $\alpha \& \beta^{[16]}$ have been found and studied in which $\alpha$ is related with oxygen regulating capacity while $\beta$ (also known as aryl hydrocarbon receptor nuclear translocation) is dimersied with $\alpha$ subunit under hypoxic condition which subsequently binds to the target genes involved in the cell survival, glycolysis, angiogenesis, erythropoesis and iron metabolism (refer Fig. 2) [17]. Polyphenols like resveratrol (4) and catechins such as EGCG (epigallocatechin gallate) (5) act through the induction of HIF-1 $\alpha$ pathways.<smiles>Oc1ccc(/C=C/c2cc(O)cc(O)c2)cc1</smiles>

And in several studies, direct relationship between hypoxia and production as well as accumulation of amyloid- $\beta$ protein, responsible for the pathogenesis of $\mathrm{AD}$, is obtained [18].
Therefore, the compounds helpful in the activation of HIF-1 $\alpha$ can play the ideal role in the management of AD too.

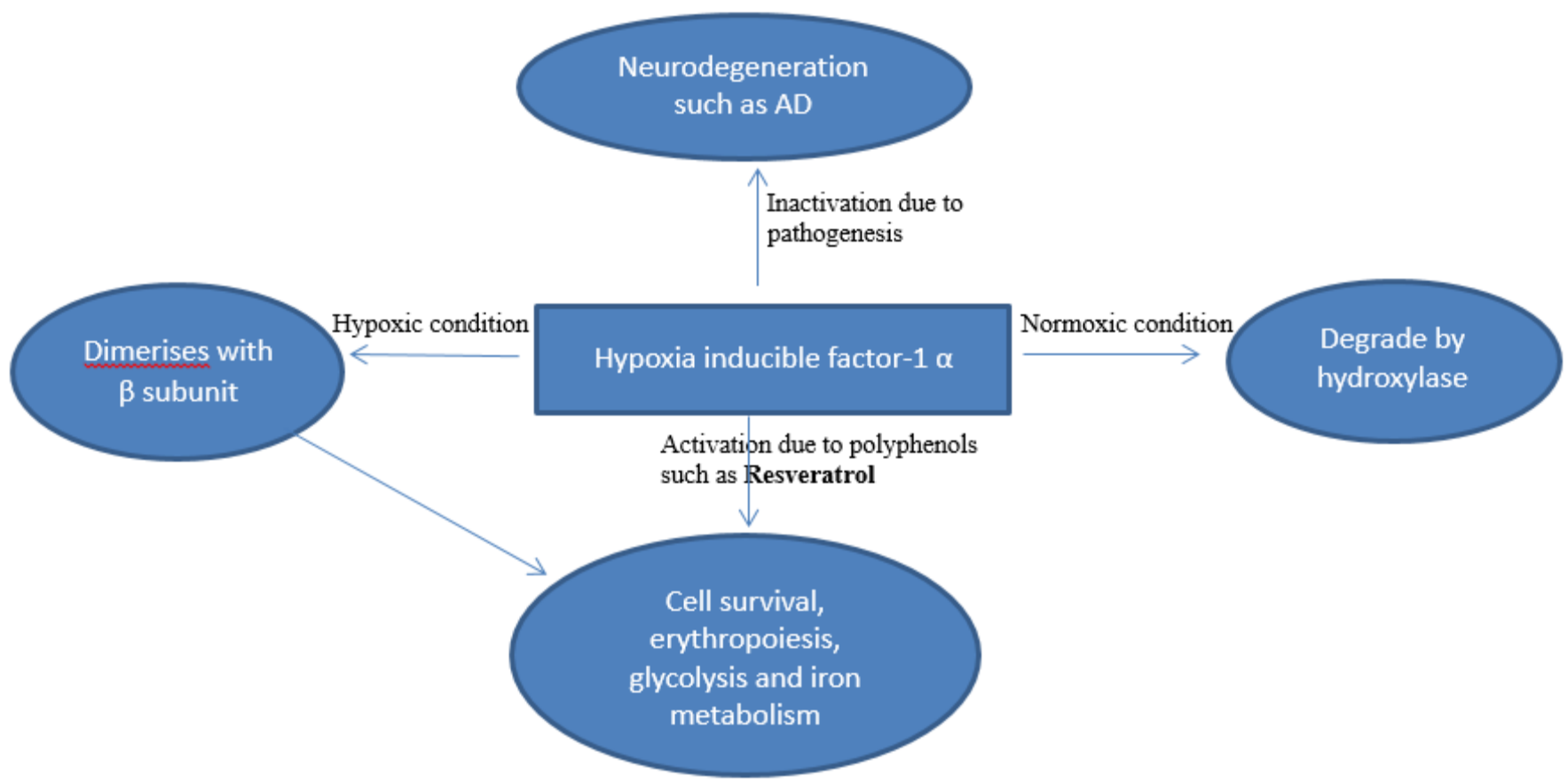

Fig 2: Behaviour of HIF-1 $\alpha$ in different conditions 
i) ROS Modulation: This is an additional mechanism through which polyphenols can show their antioxidant properties by regulating the reactive oxygen species which are responsible for the deterioration of various cell organelles in the central nervous system ${ }^{[19]}$. Further, these species are reported to reduce the various metal ions in the brain which is one of the symptomatic behaviours found in various neurodegenerative diseases such as AD, PD etc. EGCG, a major constituent in the Japanese green tea has been found as most effective in reducing the hydroxy radicals, superoxide radicals, peroxy radicals, nitric oxide, lipid free radicals and even 1, 1-dipheny 1-3-picrylhydrazy 1 free radicals. The chemistry behind such kind of behaviour of EGCG is the presence of the plenty of hydroxy groups in its structure which can act as both hydrogen donor as well as hydrogen acceptor ${ }^{[20]}$.

ii) Metal Chelation: Lipid peroxidation starts to occur in the brain under various stressed condition which can be inhibited via chelation of the metal ions such as ferrous ion by the various antioxidants like vitamin $\mathrm{E}$ and vitamin $C(8)^{[15]}$. These metals actually catalyze the oxidation of even natural antioxidants which is proceeded through the free radicals formation. Therefore, a special account of flavonoids are used in order to remove or cage such metals. Flavanoids possess 3-OH group are believed to be shown with better actvity when compared with 5$\mathrm{OH}$ group moeity. The presence of catechol ring also demonstrate better actvity than the presence of $5-\mathrm{OH}$ group which can be clearly understood by considering fisetin (6), a good iron chelator. The dual combination of 4-keto and 3-OH groups in the flavonoid structure is also responsible for the better chelating properties as seen in the case of galangin (7) ${ }^{[21]}$. By observing such kind of studies based on the structure related activities, we can expect a broad range of compounds which can make chelations with these transition metals.<smiles>O=C1O[C@H]([C@@H](O)CO)C(O)=C1O</smiles>

iii) Cell signals Alteration: There are number of cell signal pathways which are responsible for the cell survival and apoptosis under different circumstances. The major of these pathways are PI3K (phosphoinositide-3 kinase), PKA (protein kinase A), MAPK (mitogen activated protein kinase), tyrosine kinase, Akt/PKB (Akt/protein kinase B) etc. Polyphenols act on the ATP binding sites of these cascades such as mitochondrial ATPase, calcium plasma membrane ATPase, protein kinase A, protein kinase $\mathrm{C}$, topoisomerase \& benzodiazepine binding sites of GABA-A receptor and cause change in either phosphorylation or expression of the targeted genes ${ }^{[15]}$. Among all the mentioned pathways, MAPK is the most general pathway through which polyphenols produce their actions. The subclass of polyohenols such as hesperetin (9), and naringenin (10) possibly show its neuroprotective activity by inhibiting the kinases enzymes ${ }^{[22]}$. Furthermore, resveratrol is established to show its neuroprotective activity by modulating the expression of SIRT1 (sirutin) as suggested in the mice models of AD \& HD ${ }^{[23]}$. In addition, resveratrol as well as huperzin A \& EGCG are also found to be responsible for the overexpession of protein kinase $\mathrm{C}$ which leads to cause reduction in the amyloid protein which is a major target in the treatment of $\mathrm{AD}^{[24]}$.<smiles>O=C1CC(c2ccc(O)cc2)Oc2cc(O)cc(O)c21</smiles>

Quercetin (11) is a polyphenolic compound which has been reported for showing its immense activity to inhibit the PI3/Akt/PKB pathways which ultimately inhibit the synthesis of proapoptotic proteins say $\mathrm{Bcl} 2$ (B-cell lymphoma 2) and alleviate the longevity of the neuronal cells ${ }^{[25,26]}$. However, different polyphenols are being informed to target a large number of the protein kinases and other mediators of the cell signalling pathways which makes the understanding of the mechanism little bit complicated.<smiles>O=c1c(O)c(-c2ccc(O)c(O)c2)oc2cc(O)cc(O)c12</smiles> 
2. Alkaloids: Besides polyphenols, alkaloids have also shown its promising effect on treating neurodegenerative problems in in vitro and in vivo models of rats. The fruitfly (Drosophila melanogaster) model, associated with neurodegeneration such as $\mathrm{AD}$ or PD is the most demanded model in the field of CNS related studies. The possible reason behind this, might be its similarity in term of genetic elements with that of humans ${ }^{[27]}$. And it is a well-known mythology that the green leafy vegetables are not only good for nutritional care but also good as a medicinal benefit. In this regard, a study has been performed on the alkaloid extract of the leaves of Gnetum africanum (African Jointfir), commonly knowns as Okazi in Nigeria. In this study, the extract is examined on the Mn induced neurotoxic model of fruit flies and it is observed that the survival rate and the locomotor function of these flies enhance. Actually, this plant has been under traditional uses such as fever, ulcer \& diabetes and also demonstrated hypolipidermic, hypoglycemic, antioxidant, and antiinflammatory properties ${ }^{[28,29]}$.

As per the analysis, Manganese induces the neurotoxicity in the mentioned model via the following ways:-

a. Elevation in the ROS level

b. Elevation in the NO (nitric oxide) level

c. Induction in the metal catalysis

As we have already discussed that these free radical are cytotoxic and can damage various neurons and related transmitters. Therefore, the moiety which can ameliorate such free radicals will be very beneficial in order to treat various neurodegeneration. And the alkaloid extract of African jointfir is found to be able to decrease such elevated free radicals and besides, it is also reported to inhibit the acetylcholine esterase enzyme in the in vitro study of fruitfly model ${ }^{[30]}$. It produces a conception to employ this extract to treat neurodegenerative disease such as AD and dementia because inhibiting acetylcholine esterase enzyme will lead to increase the life span of acetyl choline which is responsible for the cognitive ability, memory/learning, motor function and locomotion ${ }^{[31]}$. The effect is found to be much better when the model is being cotreated with Mn sample.

And it is a well-known fact that $\mathrm{Fe}^{+2}$ is responsible for the ROS production which causes the cell damage. But in this model Mn has induced neurotoxicity by competing with the ferrous ion i.e through non-redox pathway ${ }^{[32]}$. Since there is the chemical similarity between $\mathrm{Fe}$ and $\mathrm{Mn}$ so it can be expected the jointfir extract to chelate $\mathrm{Mn}$ as well [31].

Apart from producing immune response, cell proliferation and differentiation, NO is also being reported as a proinflammatory mediator ${ }^{[33]}$. And according to the study, the alkaloid extract of African Jointfir is able to ameliorate the elevated level of NO which suggests its anti-inflammatory property ${ }^{[30]}$. So in this way, this extract can be an innovative candidate for the isolation purpose obtaining possibly a novel or known compound which is active in treating neurodegeneration.

There are several other alkaloids such as vindolicine (12) which is isolated from leaves extract of Catharanthus rosea ${ }^{[34]}$, tetrandine which is a benzylisoquinoline alkaloid [35], boldine (13) from the bark of $P$. boldus ${ }^{[36]}$, photoberberine and aporphine alkaloids from the Mahonia aquifolium ${ }^{[37]}$ and several others have been reported with antioxidant properties in different free radicals productive models. In fact, boldine $(10-100 \mu \mathrm{M})$ has been shown its efficay in ameliorating the peroxidative production which is observed by decreased in the visble luminiscence due to the reduction of TBARS (thiobarbituric acid reactive species) formation, and oxygen consumption in the in vitro model of rat's brain ${ }^{[36]}$.

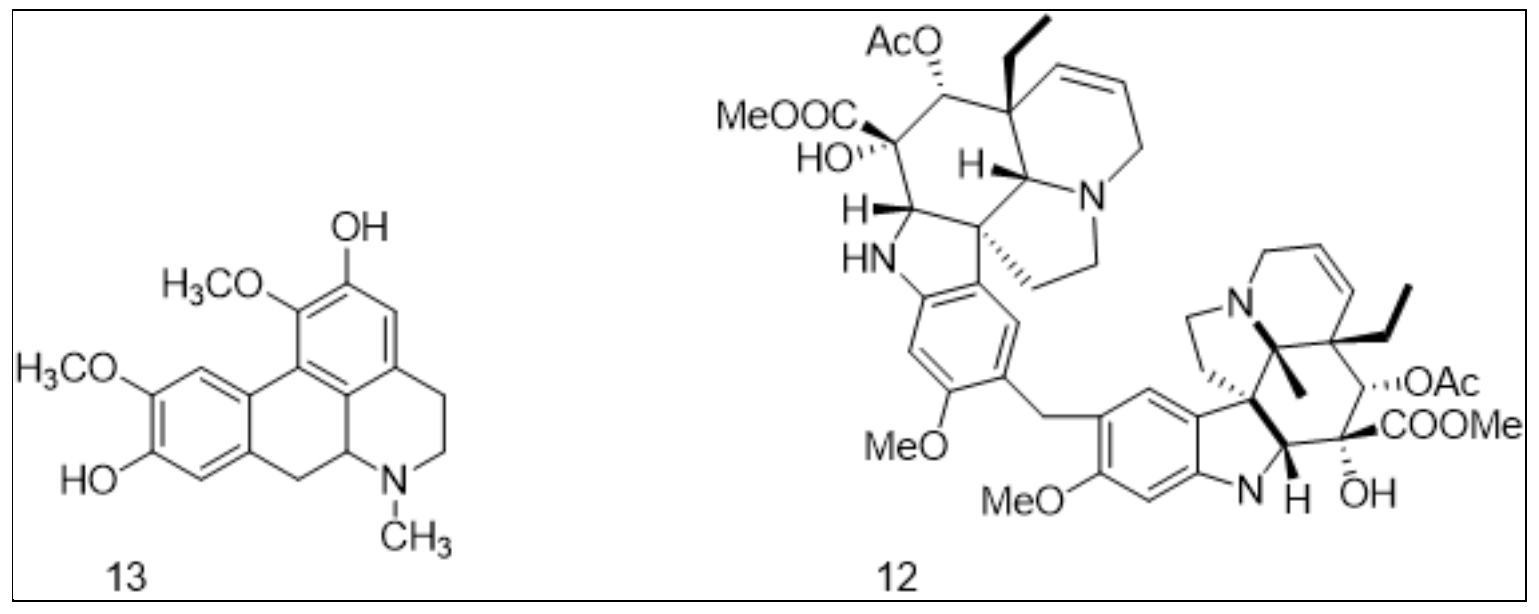

Vindolicine has revealed its scavenging activity when examined under DPPH, ORAC and peroxide induced free radicals assays in the $\beta$-TC6 cell lines of mouse pancreatic model. These assays have been performed taking quercetin as the control and it is reported that this alkaloid is much less active when compare with the standard one ${ }^{[34]}$.

As we know the caffeine (14) is one of the known compound useful in the memory enhancement and cognition improvement. There are several dietary sources of caffeine such as caffeinated soft drinks, chocolates, cocoa etc. ${ }^{[38]}$. In one of the study, the synergistic effect of caffeine on the anticholinesterase activity of Donepezil has been observed in the in vitro model of the rat. It is found that caffeine 50-100 $\mathrm{mg} / \mathrm{kg}$ body weight of the rat models causes the drastic enhancement of the anticholinesterase activity of Donepezil in addition with its antioxidant property as well ${ }^{[39]}$. In this study, alone caffeine is reported to inhibit the cholinesterase enzyme at concentration. 


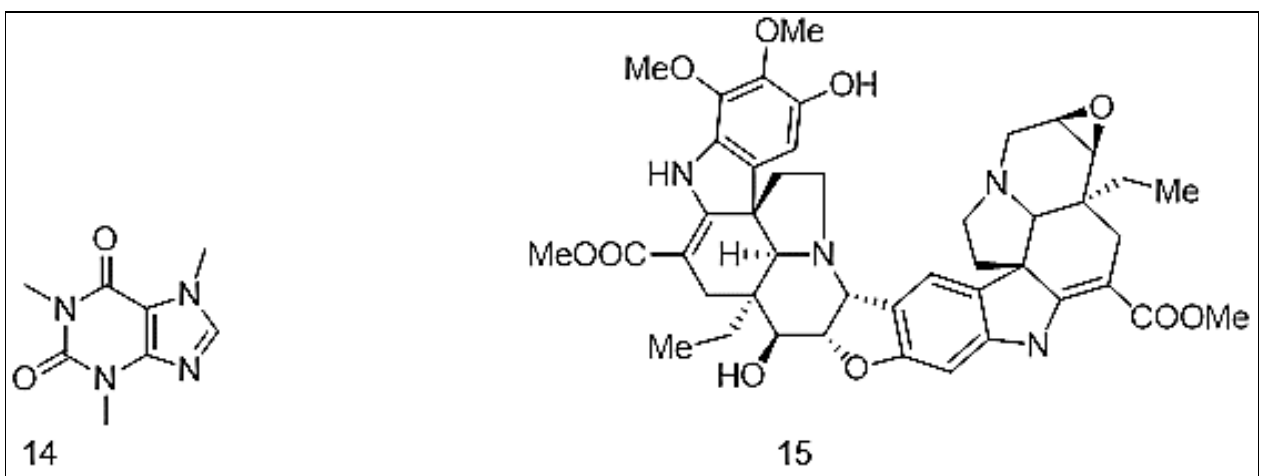

In another study, Sasazawa and coworkers worked on conophylline (15), one of the novel compound of that time and reported its autophagical activity. This compound was found to be active in suppressing the aggregation of the proteins responsible for the neurogenerative disease such synuclein in PD or huntingtin in HD in m-TOR (mammalian target of rifampicin) independent manner ${ }^{[40]}$. In this way, this compound was found to be effective in eluding the cell death while treating any neurodegenerative disease as in case of neurotoxin, $\mathrm{MPP}^{+}$(1-methyl-4-phenylpyridinium). This experiment was done in the rat pheochroma $\mathrm{PC} 12$ cytoma cells of PD model.

Alkaloids are also being reported to inhibit the enzyme known as monoamine oxidase enzymes (MAO), a member of flavin dependent metabolic enzymes. This possess two isozymes such as MAO-A \& MAO-B and are responsible for the conversion of the various biogenic and and xenobiotic amines into its oxidative produts as well as peroxide radicals as byproduct (refer Fig. 3) ${ }^{[41]}$.

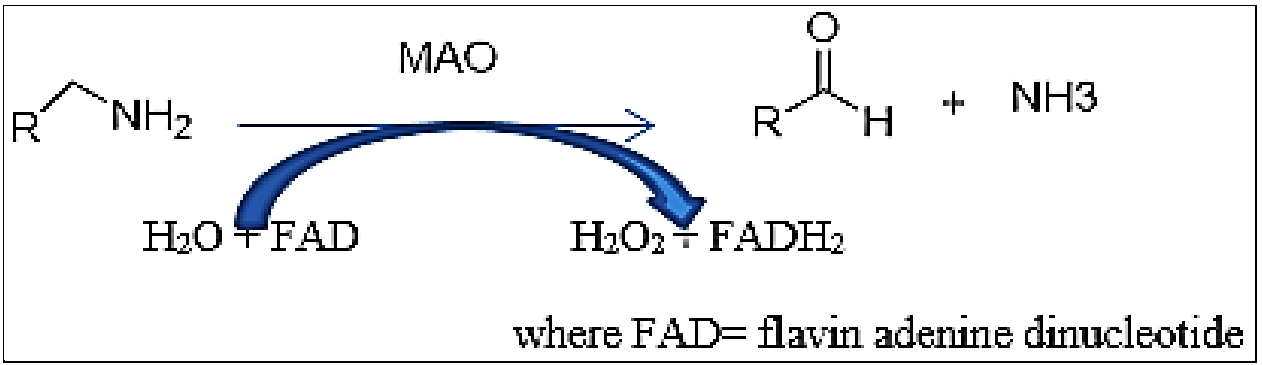

Fig 3: Oxidation of amines by MAO

And, the produced peroxide as usual causaes oxidative stress to the neurons which leads to the various neurological disorders. Therefore, inhibiting this enzyme present on the mitochondrial membrane will be a good propective in order to treat and manage different neurodegenerative diseases such as HD, PD, AD and dementia. The subcategories of alkaloids which can act as MAO inhibitors area. Indole alkaloids such as $\beta$-carboline \& monoterpene alkaloids, b. isoquinoline alkaloids say jatrorrhizine \& berberine, c. piperidine alkaloids, i.e. guineensine \& piperine, d. tropane alkaloids say atropine \& hyoscine etc. $\beta$-carboline alkaloid say harmala from Peganum harmala is found to be countervailed both the isozymes of MAOs and various derivatives have been studied in order to raise the selectivity. For example, selective MAOA inhibitors are effective in treating the depression but selective MAO-B inhibors are used frequently to treat Parkinson's disease.

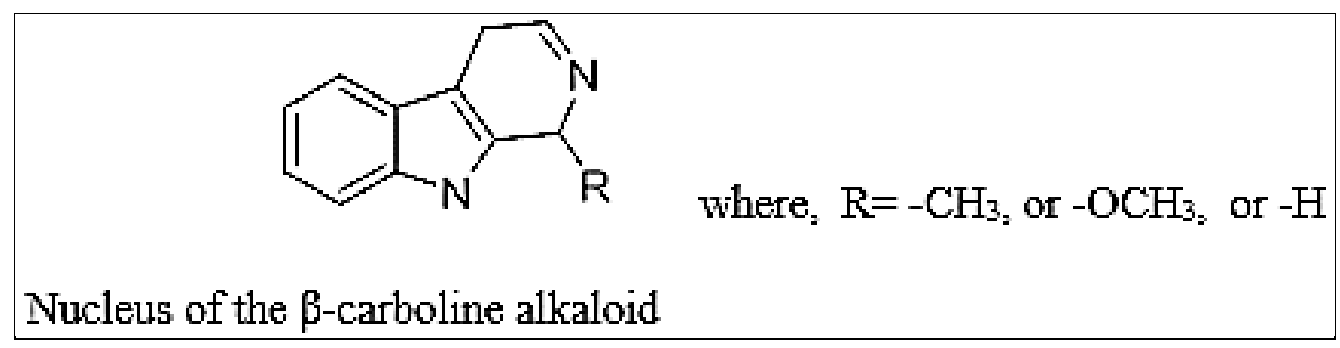

3. Vitamins: Vitamins are the organic compounds that cannot be or partially synthesized by the body which are very essential for the health and well-being. The diets deficient in vitamins, other antioxidants and unsaturated fatty acids lead to increase the susceptibility to neurodegenerative problems ${ }^{[42]}$. Different types of diseases can occur even when a single vitamin is missing in the body such as night blindness due to vitamin A, beri-beri due to vitamin B, scurvy due to viamin $C$, rickets due to vitamin $\mathrm{D}$ and so on ${ }^{[43]}$. But the major vitamins which are nutritious for the central nervous system are vitamins $\mathrm{C}, \mathrm{D} \& \mathrm{E}$. These vitamins play a major role in maintaining the health of the neurons and also help in avoiding the various mechanisms which can cause various neurodegenerative diseases such as cognitive impairment, AD or PD. According to the Food and Nutrition Board, the elderly people associated with various neurological disorders can take upto $2000 \mathrm{mg} /$ day and $1000 \mathrm{mg} /$ day of vitamins C \& E respectively in order to avoid any toxicity. ${ }^{[44]}$.

a. Vitamin C: This vitamin is termed alternatively with 
ascorbic acid, dehydroascorbic acid or any other ascorbate. The list of the components in which ascorbic acid is found are the citrus fruits say lemon, broccoli, pepper, cauliflower and potatoes ${ }^{[43]}$. The most known disease caused due to deficiency of vitamin $\mathrm{C}$ is scurvy which is characterized by athralgias, bleeding and improper wound healing. Ascorbic acid or vitamin $\mathrm{C}$ is the compound having capability to ameliorate the free radicals produced during any oxidative stress. And it is found in a study that this compound can increase the viabilty of peroxide induced PC 12 cells in a dose dependent manner ${ }^{[45]}$. Vitamin $\mathrm{C}$ shows the scavenging activity in the aqueous environment and can act as the modulator of the Vitamin E scavenging activity.

In a study, it is found that chronic alcoholism is the cardinal feature in FAS (Fetal Alchol Syndrome) which is associated with the decrease in the dopamine level \& probably oxidative stress causing various neurodevelopmental deficiencies in the fetus ${ }^{[46]}$. Therefore the hippocampal part of pregnant Sprague-Dawley rats were cultured \& exposed with ethanol \& PTZ (pentyleneterazol) and the effect of vitamin $\mathrm{C}$ was observed. Vitamin $\mathrm{C}$ showed its neuroprotective propert by reducing the damage caused by ethanol and PTZ at gestational day 17.5. Furthermore, it was revealed that the cotreatment (vitamin $\mathrm{C}+\mathrm{PTZ}+$ alcohol) effetively improves the prenatal development by reducing PTZ and alcohol induced apoptotic neurodegeneration. Besides, increase in the cell proliferation and cell survival by inducing the antiapoptotic proteins say Bcl-2 were the additional merits observed in that particular experiment ${ }^{[47]}$. But the dose of the vitamin $\mathrm{C}$ is very much important to be considered here as it should not interfere with the natuarlly occuring oxidative process probably important for the fetus ${ }^{[48]}$.

Vitamin $\mathrm{C}$ has been investigated to treat the numerous CNS disorder as follows:-

i) Alzheimer's Disease: As we know this disorder is the effect of both genetic and lifestyle combination charaterized by the accumulation of amyloid- $\beta$ protein in the brain. In a study, it is observed that the alzheimer's patients are found to have lower plasma and CSF (Cerebrospinal Fluid) ascorbate level ${ }^{[49,50]}$. It has been evidenced that the orally administered ascorbate can protect the CA1 area of hippocampus of the rat's brain from the oxidative damage. It was also found that the SHSY5Y neuroblastoma cells could be protected from apoptosis induced by $\beta$-amyloid protein ${ }^{[51,52]}$. The ascorbate has also been reported to act as acetylcholine estrase inhibitor, the most prominent way to treat AD ${ }^{[53]}$.

ii) Parkinson's Disease: Ascorbate has been found to improve the durability of levodopa which can then be converted into dopamine and can raise the dopamine level in the elderly patients which is a key line of treatment in the PD ${ }^{[54]}$. The oxidative stress induced by $\mathrm{MPP}^{+}$(1-methyl-4-phenyl pyridinium) in various Parkinson models is reportedly protected by the ascorbate administration ${ }^{[55]}$.

iii) Huntington's Disease: It has been found the release of the ascorbate declines in the brain of the mices express genes for the Huntington's disease which can be reverted by administering the ascorbate injection ${ }^{[56]}$.

b. Vitamin E: Vitamin E, also known as tocopherol is a group of lipid soluble tocol or tocotrienol derivaties. Out of which, $\alpha$-tocopherol is the most concerned compound for the human health [43]. Although the clinical deficiency of vitamin $\mathrm{E}$ is not very common yet the only known disease due to primary deficiency of vitamin $\mathrm{E}$ is AVED (Ataxia with viamin $\mathrm{E}$ deficiency) caused due to the mutations in the TTP (Tocopherol Transfer Protein) [57, 58]. TPP is a protein which is physiologically available to facilitate the selective secretion of $\alpha$-tocopherol from hepatocytes to the lipoproteins that deliver the vitamin to the non-hepatic tissues [59]. Cholestatic liver disease, short bowl syndrome, cystic fibrosis, abetalipoproteinemia, Tangier's disease etc. are the fat malabsorption disorder which are generally caused due to secondary vitamin E deficiency ${ }^{[60-63]}$. The structure of tocopherol has already been discussed in this chapter and its metal chelating activity is described. The evidences of the reaction of vitamin $\mathrm{E}$ with the peroxyl radicals suggests its in vivo antioxidant properties to prevent any tissue damage ${ }^{[64]}$. In fact, vitamin $\mathrm{E}$ is the most important lipid soluble antioxiant in plasma and Red Blood Cells which protects lipid from its peroxidation ${ }^{[65]}$. In different study, it has been mentioned that vitamin $\mathrm{E}$ works as a chain antioxidant which inhibits the polyunaturated fat in the membrane and plasma lipoproteins to initiate any free radical reaction ${ }^{[66]}$. In this section, we will discuss about the role of vitamin $\mathrm{E}$ in different neurological disorder management and the possible mechanism behind.

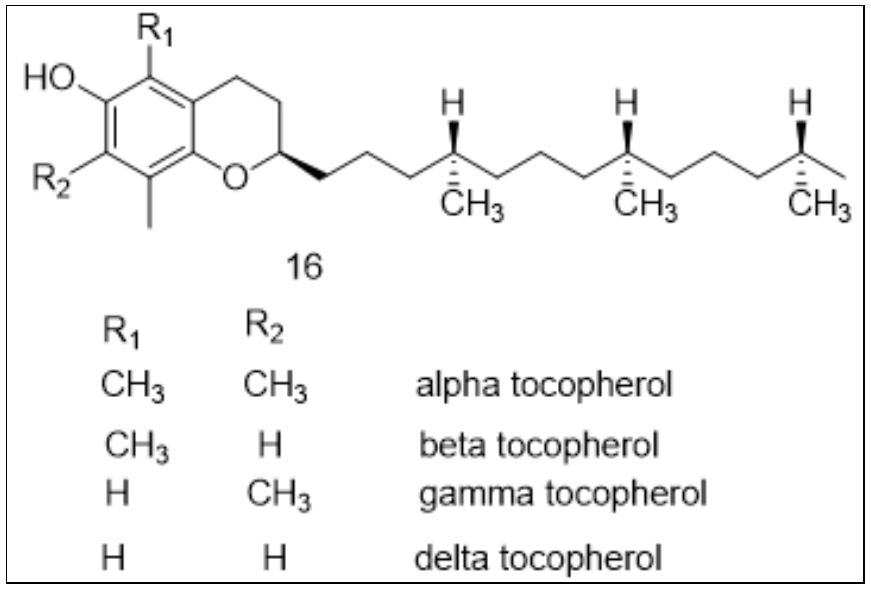

In one of the study, the capacity of quenching singlet oxygen by different tocopherols was observed and the following sequence was obtained:- alpha tocopherol > beta tocopherol > gamma tocopherol > delta tocopherol [67]. The possibe chemistry behind this antioxidant activity of tocopherol is the presence of 6-OH group in the chromane ring (see above) because the activity diminishes or completely vanishes as this -OH group is replaced by any ester or ether ${ }^{[68]}$.

The effect of intake and concentration of vitamin $\mathrm{E}$ in the brain have assessed its importance towards the neurological function and its efficiency in different studies. In a study, the role of vitamin $\mathrm{E}$ in the inhibition of the neurotoxicity due to accumulation of the amyloid beta protein is demonstrated [69, 70]. The decrease in the vitamin E concentration due to any external or internal stimuli such as any baterial infection, exposure to any toxins, or metabolic changes such as increased in homocysteine etc. could increase free radical reaction, alter the normal brain function and speed up the progression of dementia in AD [44,71,72]. This developed an idea to consider tocopherol's ability to protect neurons from oxidative stress which is documented in multiple studies [73, 74].

c. Vitamin $\mathbf{D}^{*}$ : It has been a long time when vitamin D has 
shown its role in the neuroimmunomodulation and reported to have multiple biological targets (VDR, i.e., vitamin D receptor) in order to overcome with any of the CNS disorders [75]. Vitamin D (17) (especially cholecalciferol, i.e. vitamin $D_{3}$ ) can be synthesised in the skin under the exposure of ultraviolet rays and therefore often avoided to consider it into the classical definition of vitamins ${ }^{[76]}$.

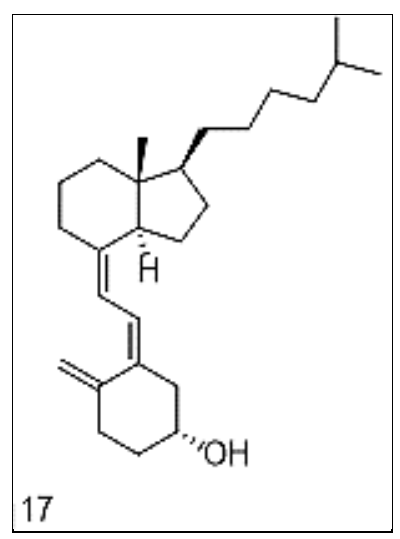

The major source of vitamin D are fat fish flesh, fish liver oil, mlk, eggs of hen etc. and the major function of vitamin D is to maintain the calcium and phosphorus level by altering their absorption in the small intestine, maintaining the equlibrium with the bones and modulating the immune system ${ }^{[77]}$. The deficiency of vitamin D is majorly characterized by rickets in the children and osteomalacia in adults ${ }^{[43]}$. And the list of the functions reportingly performed by the application of vitamin $\mathrm{D}$ in order to treat various neuropathologies but not through antioxidant pathways are as follows:-

i) In a study done by J. Brown \& company, it has been demonstrated that the vitamin $\mathrm{D}$ can play a vital in stimulating the synthesis of neurotrophic agents such as neurotrophin 3 , nerve growth factor, glial cell-line derived neurotrophic factor and other important moeities which help correspondingly in the neuronal growth in in vitro rat hippocampal cell cultures ${ }^{[78]}$. This neuroprotective action of vitamin $\mathrm{D}$ was found to be either due to the regulation of calcium dependent voltage channels or synthesis of calcium related cytoplasmic proteins such as calbindin ${ }^{[79,80]}$.

ii) Vitamin $\mathrm{D}$ has been reported in eludng the VDRdependent immunosuppression including rise in the cytokine level, macrophages and polynuclears in the mice model by inhibiting the expression of major proteins involved in the auotimmune process of the nervous system $^{[79,81]}$.

iii) Furthermore, it was found that the public associated with the higher altitude region \& born during winter season, are more susceptible to get the disorder, Schizophrenia. Lower amount of 1, 25-dihydroxy $\mathrm{D}_{2}$ (active form of vitamin D) in the maternal plasma which deteriorate the neuroformation and favoring the occurrence of psychosis, could be the possible reason behind such scenario ${ }^{[82,83]}$.

iv) In several other studies, the correletaion between vitamin $\mathrm{D}$ and depressive subjects is established. According to which, the subjects with deficiency of 25-hydroxy $\mathrm{D}_{2} \&$ 1,25-dihydroxy $\mathrm{D}_{3}$ concentration in their body are prone to have depression ${ }^{[84-86]}$. In another study it was found that the seasonal depressive subjects given with 100000 IU of vitamin D showed better results when compared with the same subjects treated with phototherapy ${ }^{[87]}$.

v) An article has confirmed the reduction of the seizure episodes in epilepsy while treating with vitamin D supplementation ${ }^{[81]}$. This can be justified by considering the mechanism of action of valproic acid (commonly used in epilepsy), which is an inhibitor of cytochrome P450, an enzyme responsible for the catabolism of 25hydroxy $\mathrm{D}_{2}$ to inactive form ${ }^{[88]}$.

4. Terpenoids: These are the class of compounds which are identified as the integral multiple of isoprene units $\left(\mathrm{C}_{5} \mathrm{H}_{8}\right)$ and then named accordingly such as monoterpenoid, sesquiterpenoid, diterpenoid, sesterpenoid, triterpenoid and so on. Terpenoids have also some historical evidences of antioxidant and antiinflammatory properties which can lead their importance in neurological background ${ }^{[89]}$. The presence of the huge number of alternate duble bonds is possibly the factor behind the free radical scavenging activity of terpenoids ${ }^{[90]}$.

Lycopene (18), a terpenoid which is enriched in the variety of substance such as tomato, potato, water-melon, apricot etc. has established its antioxidant or free radical scavenging activity is more than that of $\beta$-carotene and tocopherols ${ }^{[91]}$. An inverse relationship between serum lycopene concentration and and lipid oxidation has been demonstrated and found that instant absorption of tomato lycopene reduces the possibility of oxidative damage to the lipids, proteins, DNA etc. ${ }^{[92]}$. Lycopene is supposed to act as an antioxidant which may reduce the dementia symptoms attributed in $\mathrm{AD}$ by ameliorating the degree of disturbance in antioxidant balance ${ }^{[93]}$.

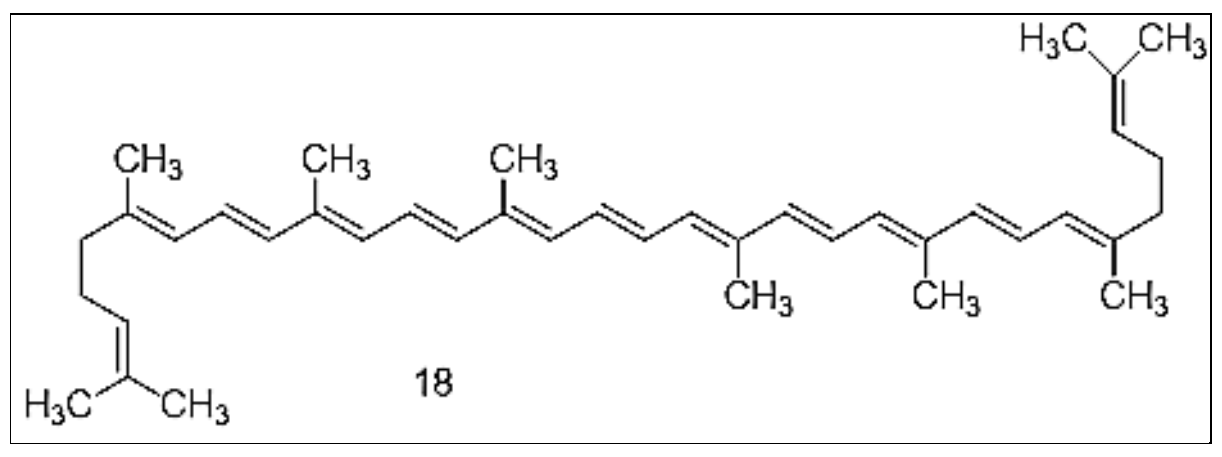

Studies have investigated that lycopene has the potential to cross the BBB and can act on neurons directly or indirectly through modulating the addition of peroxy radicals to the polyene chains, electron capture by pigment, hydrogen abstraction from allylic positions ${ }^{[94,95] \text {. }}$

One of the investigations has suggeted the role of terpenoids in the neuroprotection of transient global cerebral ischemic (tGCI) rats. This study was based on Lupeol, a pentacylcic 
triterpenoid isolated from the leaves of Hygrophila auriculata and some of its fractions. This plant is marked

as 'Rasayana' in Ayurveda which means drugs for the treatment of neurological disorders. Furthermore, the ethanolic terpenoid fraction of this plant has been reported to reverse the reduction in the glutathione (GSH) activity in cortex and hippocampal regions of the brain ${ }^{[96]}$. GSH is responsible for the synthesis and release of various molecules such as glutamate and GABA which coordinate the NMDA \& non-NMDA activity ${ }^{[97]}$. And it is found in various studies that the deficiency of glutamate and related compounds lead to cause neurological impairments ${ }^{[98]}$.

In another study, the application of Curcuma oil (isolated from the rhizomes of Curcuma longa) on the transient focal ischemic brain of rats was demonstrated with the reduction in the concentration of reactive oxygen species and peroxynitrite which significantly showed its antioxidant properties. Therefore, this can be employed in order to delay the neuronal death ${ }^{[99]}$.

Lutein (19) and zeaxanthin (20) are the two compounds of the same abovementioned class have been found in association with neural perfromance. These are the plant pigments possibly helpful in maintaining the MPOD (Macular Pigment Optical Density), the retinal carotenoids which have direct relationship with the modulation of brain health and cognition strength. In a study, it has been found that the preadolescents with higher MPODs tend to respond superior in a given cognitive load as compared with that of adolescents with lower MPODs ${ }^{[100]}$.<smiles>CC1=CC(O)CC(C)(C)C1/C=C/C(C)=C/C=C/C(C)=C/C=C/C=C(C)/C=C/C=C(C)/C=C/C1=C(C)CC(O)CC1(C)C</smiles>

The in vivo effect of POJ (pasteurized orange juice; 2 varieties, i.e. Cara Cara \& Bahia) on the transgenic alzheimer's model of C. elegans was observed and concluded its resistive property towards oxidative stress by acting through the trancription factor SKN-1. Besides, it was found that POJ was responsible for the delayed $\beta$-amyloid induced paralytic symptoms and boosted the longevity of the neurons. Furthermore, the obtained results were more effective for the Cara Cara rather than the Bahia possibly due to its higher content of carotenoids such as zeaxanthine, lycopene, $\beta$ carotene etc.

5. Others: In a study, melatonin (21) which is naturally occuring hormone responsible for the regulation of sleep cycle, is found to be responsible for the direct or indirect benefits in AD. The effect was proposed due to its antiamyloidogenic property, interaction with apolipoprotein $\mathrm{E} 4$, and $\beta$-amyloid antagonism ${ }^{[101-103]}$. The major external sources of melatonin are fruits \& vegetables (potaotoes, cucumber, pomegranate, asparagus, apricot etc.), grains (rice $\&$ barley) and nuts $\&$ seeds (walnuts, peanuts, flax seeds) ${ }^{[9]}$.
Several fractions of the leaves of Ginkgo bolibo have been reported with antioxidant property and found toxic to $\beta$ amyloid protein and reducing the NO induced neuronal death [104]. This effect was probably due to the various flavonoids and terpenoids which further demonstrated the cognition enhancing property in $\mathrm{AD}^{[105]}$.

In various studies it has been established the people with frequent intake of coffee and cigarette have minimum risk of PD. It has been investigated that nicotine consumption stimulates the release of dopamine in the striatum and preserves the nigral neurons \& striatal dopamine level in animals. It has been informed that caffeine and the related compound theophylline are the adenosine $\mathrm{A}_{2 \mathrm{~A}}$ receptor antagonist which lead to improve the motor function in the PD patients ${ }^{[106,107]}$.

$\gamma$ - mangostin (22), a major compound from the fruits of Gercinia mangostana has been found effective in reducing the neurotoxicity by inhibitng the peroxide induced ROS generation, DNA fragmentation, and lipid peroxidation ${ }^{[108]}$.<smiles>CC(C)=CCc1c(O)cc2oc3cc(O)c(O)c(CC=C(C)C)c3c(=O)c2c1O</smiles> 
Even the marine creatures have been considered as the excellent source of antioxidant compounds which can play a vital role in the management of various neurological maldies [109]. A macrocyclic compound (23) isolated from an algae Sargassum micracanthum has shown its antioxidant potential and can be clamied to reduce the free radicals produced during oxidative stress in any neurodegenerative disease, say AD [110]. Another compound from marine source, i.e., manzamine-A (24) has been marked as antineurogenic compound with potent anti-inflammatory and low toxicity properties ${ }^{[110]}$.

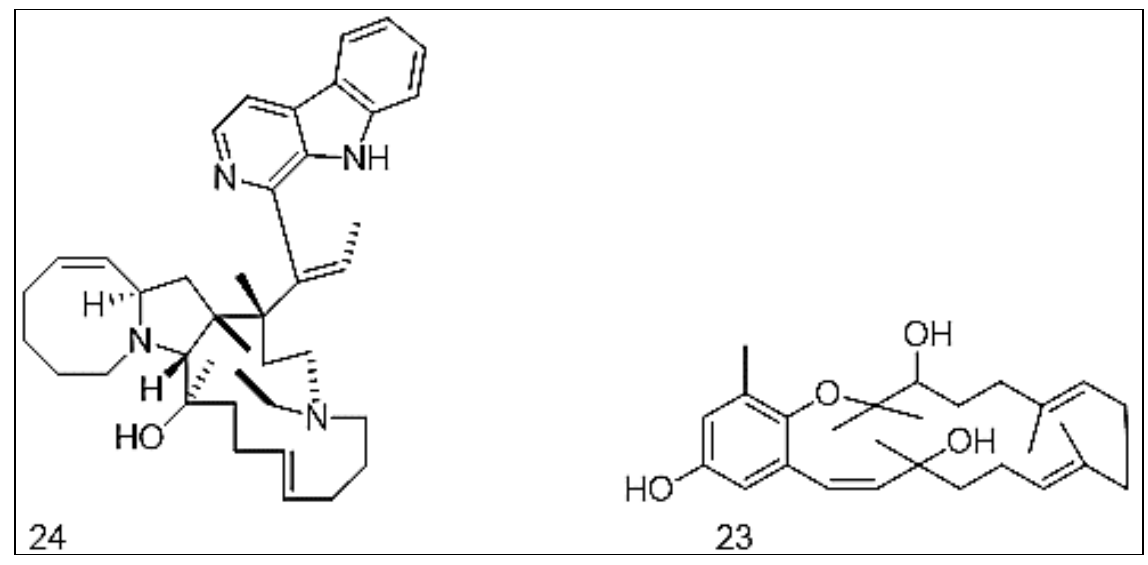

In a study, the action of green tea extract on N-methyl-4phenyl-1, 2, 3, 6-tetrahyropyridine induced Parkinson's mice model was observed. The study concluded that the extract was responsible for reduction in the loss of dopaminergic neurons in substantia Nigra along with the increment of striatal dopamine and tyrosine hydroxylase levels. The possible cause behind this property was supposed to be due to the presence of (-)-epigallocatechin-3-gallate in the extract which is a wellknown polyphenolic compound ${ }^{[111]}$.

\section{Conclusion}

Neurological disease is considered to be the second leading cause of deaths after cardiovascular disease ${ }^{[112]}$. Therefore, it should be a centre of attention in order to keep people healthy and free from any CNS maladies. And there has been plenty of evidences behind the role of oxidative stress in various kinds of neurodegenerative diseases such AD, PD, HD and so on. But it is a truth that the gap between the clinical and preclinical evidences of treatment by using single antioxidant in such neudegenerative diseases has been observed so many times ${ }^{[113]}$. Therefore, it has been suggested that use of multiple antioxidant can play a vital role in treating any neurological disorder rather than the use of single antioxidant [114]. In this context, it can be assumed to use fruits, vegetables, ginkgo extract, and beverages such as green tea, POJ will be a better option in order to treat any neurological disease since these contain multiple antioxidants. Although, this chapter concluded various polyphenols, alkaloids, vitamins and terpenoids as the major natural bioactive antioxidants which can be used to provide prophylactic as well as curative treatment in the various neurodegenerative diseases such as AD, PD, HD, \& so on. Furthermore, this manuscript has dealt with various compounds originated from the marine creatures which had been proven descent antioxidants and could be a pivotal neuroprotective agents.

\section{Acknowledgements}

The authors are thankful to the staff of R.K College of Pharmacy for their continuous support and inspiration.

\section{References}

1. Mendonça-Junior FJ et al., Natural bioactive products with antioxidant properties useful in neurodegenerative diseases. Oxidative medicine and cellular longevity, 2019.

2. Dua T et al., Global burden of neurological disorders: estimates and projections. Campanini B (Editora). Neurological disorders: Public Health Challenges. Ginebra: Banco Mundial, 2006, 27-39.

3. Balsano C. A Alisi, Antioxidant effects of natural bioactive compounds. Current pharmaceutical design. 2009; 15(26):3063-3073.

4. Cadenas E. Biochemistry of oxygen toxicity. Annual review of biochemistry. 1989; 58(1):79-110.

5. Organization WH. Dementia: a public health priority. World Health Organization, 2012.

6. Dalton TP, Shertzer HG, Puga A. Regulation of gene expression by reactive oxygen. Annual review of pharmacology and toxicology. 1999; 39(1):67-101.

7. Limón-Pacheco J, Gonsebatt ME. The role of antioxidants and antioxidant-related enzymes in protective responses to environmentally induced oxidative stress. Mutation Research/Genetic Toxicology and Environmental Mutagenesis, 2009; 674(1-2):137147.

8. McCall MR, Frei B. Can antioxidant vitamins materially reduce oxidative damage in humans? Free Radical Biology and Medicine. 1999; 26(7-8):1034-1053.

9. Chen P, Osborn BL. F.p. Abramson, Examining the origin of melatonin from a" natural" source by isotope ratio mass spectrometry with liquid chromatographic introduction. Journal of AOAC International. 1998; 81(1):40-43.

10. Caruana M, Cauchi R, Vassallo N. Putative role of red wine polyphenols against brain pathology in Alzheimer's and Parkinson's disease. Frontiers in nutrition. 2016; $3: 31$.

11. Kay CD. The future of flavonoid research. British Journal of Nutrition. 2010; 104(S3):S91-S95.

12. Chen ZX et al., Borneol for regulating the permeability of the blood-brain barrier in experimental ischemic stroke: preclinical evidence and possible mechanism. Oxidative medicine and cellular longevity, 2019.

13. Abramson SN et al., Onchidal: a naturally occurring irreversible inhibitor of acetylcholinesterase with a novel mechanism of action. Molecular pharmacology. 1989; 
36(3):349-354.

14. Anwar H, Hussain G, Mustafa I. Antioxidants from natural sources. Antioxidants in foods and its applications, 2018, 3-28.

15. Ebrahimi A, Schluesener H. Natural polyphenols against neurodegenerative disorders: potentials and pitfalls. Ageing research reviews. 2012; 11(2):329-345.

16. Ratcliffe PJ et al., Oxygen sensing, hypoxia-inducible factor-1 and the regulation of mammalian gene expression. Journal of Experimental Biology. 1998; 201(8):1153-1162.

17. Hofer T, Wenger R, Gassmann M. Oxygen sensing, HIF$1 \alpha$ stabilization and potential therapeutic strategies. Pflügers Archiv-European Journal of Physiology. 2002; 443(4):503-507.

18. Zhang $\mathrm{X}$, Le $\mathrm{W}$. Pathological role of hypoxia in Alzheimer's disease. Experimental neurology. 2010; 223(2):299-303.

19. Higuchi A et al., Inhibitory activity of epigallocatechin gallate $(\mathrm{EGCg})$ in paraquat-induced microsomal lipid peroxidation-a mechanism of protective effects of EGCg against paraquat toxicity. Toxicology, 2003; 183(13):143-149.

20. Guo Q et al., ESR study on the structure-antioxidant activity relationship of tea catechins and their epimers. Biochimica et Biophysica Acta (BBA)-General Subjects. 1999; 1427(1):13-23.

21. Van Acker SA et al., Structural aspects of antioxidant activity of flavonoids. Free Radical Biology and Medicine. 1996; 20(3):331-342.

22. Sabarinathan D, Mahalakshmi P, Vanisree AJ. Naringenin, a flavanone inhibits the proliferation of cerebrally implanted C6 glioma cells in rats. Chemicobiological interactions. 2011; 189(1-2):26-36.

23. Pallàs $\mathrm{M}$ et al., Resveratrol and neurodegenerative diseases: activation of SIRT1 as the potential pathway towards neuroprotection. Current neurovascular research, 2009; 6(1):70-81.

24. Etcheberrigaray $\mathrm{R}$ et al., Therapeutic effects of PKC activators in Alzheimer's disease transgenic mice. Proceedings of the National Academy of Sciences. 2004; 101(30):11141-11146.

25. Datta SR Brunet A, Greenberg ME. Cellular survival: a play in three Akts. Genes \& development, 1999; 13(22):2905-2927.

26. Spencer JP, Rice-Evans C, Williams RJ. Modulation of pro-survival Akt/protein kinase B and ERK1/2 signaling cascades by quercetin and its in vivo metabolites underlie their action on neuronal viability. Journal of Biological Chemistry, 2003; 278(37):34783-34793.

27. Adams MD et al., The genome sequence of Drosophila melanogaster. Science. 2000; 287(5461):2185-2195.

28. Morebise $\mathrm{O}$ et al., Antiinflammatory property of the leaves of Gongronema latifolium. Phytotherapy Research. 2002; 16(S1):75-77.

29. Ogundipe O et al., Hypoglycemic potentials of methanolic extracts of selected plant foods in alloxanized mice. Plant Foods for Human Nutrition. 2003; 58(3):1-7.

30. Oboh $\mathrm{G}$ et al., Effect of Alkaloid Extract from African Jointfir (Gnetum africanum) Leaves on ManganeseInduced Toxicity in Drosophila melanogaster. Oxidative medicine and cellular longevity, 2018.

31. Peres TV et al., Manganese-induced neurotoxicity: a review of its behavioral consequences and neuroprotective strategies. BMC Pharmacology and Toxicology. 2016; 17(1):57.

32. Farina $\mathrm{M}$ et al., Metals, oxidative stress and neurodegeneration: a focus on iron, manganese and mercury. Neurochemistry international. 2013; 62(5):575594.

33. Farombi EO et al., Garcinia kola seed biflavonoid fraction (Kolaviron), increases longevity and attenuates rotenone-induced toxicity in Drosophila melanogaster. Pesticide biochemistry and physiology. 2018; 145:39-45.

34. Tiong SH et al., Antidiabetic and antioxidant properties of alkaloids from Catharanthus roseus (L.) G. Don. Molecules. 2013; 18(8):9770-9784.

35. Seow W et al., Antiphagocytic and antioxidant properties of plant alkaloid tetrandrine. International Archives of Allergy and Immunology. 1988; 85(4):404-409.

36. Speisky $\mathrm{H}$ et al., Antioxidant properties of the alkaloid boldine in systems undergoing lipid peroxidation and enzyme inactivation. Biochemical pharmacology. 1991; 41(11):1575-1581.

37. Mišík V et al., Lipoxygenase inhibition and antioxidant properties of protoberberine and aporphine alkaloids isolated from Mahonia aquifolium. Planta medica. 1995; 61(04):372-373.

38. Mitchell DC et al., Beverage caffeine intakes in the US. Food and Chemical Toxicology. 2014; 63:136-142.

39. Oboh G, Ogunsuyi OB, Olonisola OE. Does caffeine influence the anticholinesterase and antioxidant properties of donepezil? Evidence from in vitro and in vivo studies. Metabolic brain disease. 2017; 32(2):629639.

40. Sasazawa Y et al., Conophylline protects cells in cellular models of neurodegenerative diseases by inducing mammalian target of rapamycin (mTOR)-independent autophagy. Journal of Biological Chemistry. 2015; 290(10):6168-6178

41. Passos CDS et al., Alkaloids as inhibitors of monoamine oxidases and their role in the central nervous system, in Studies in Natural Products Chemistry, Elsevier, 2014, 123-144.

42. Ramesh BN et al., Neuronutrition and Alzheimer's disease. Journal of Alzheimer's Disease, 2010; 19(4):1123-1139.

43. Kraemer $\mathrm{K}$ et al., Introduction: the diverse and essential biological functions of vitamins. Annals of Nutrition and Metabolism. 2012; 61(3):185-191.

44. Martin A et al., Roles of vitamins $\mathrm{E}$ and $\mathrm{C}$ on neurodegenerative diseases and cognitive performance. Nutrition Reviews. 2002; 60(10):308-326.

45. Heo HJ, Lee CY. Protective effects of quercetin and vitamin $\mathrm{C}$ against oxidative stress-induced neurodegeneration. Journal of Agricultural and Food Chemistry. 2004; 52(25):7514-7517.

46. Ikonomidou $\mathrm{C}$ et al., Ethanol-induced apoptotic neurodegeneration and fetal alcohol syndrome. Science. 2000; 287(5455):1056-1060.

47. Naseer $M$ et al., Vitamin C protects against ethanol and PTZ- induced apoptotic neurodegeneration in prenatal rat hippocampal neurons. Synapse. 2011; 65(7):562-571.

48. Cohen-Kerem R, Koren G. Antioxidants and fetal protection against ethanol teratogenicity: I. Review of the experimental data and implications to humans. Neurotoxicology and teratology. 2003; 25(1):1-9.

49. Rivière $\mathrm{S}$ et al., Low plasma vitamin $\mathrm{C}$ in Alzheimer 
patients despite an adequate diet. International journal of geriatric psychiatry. 1998; 13(11):749-754.

50. Schippling $\mathrm{S}$ et al., Increased lipoprotein oxidation in Alzheimer's disease. Free Radical Biology and Medicine. 2000; 28(3):351-360.

51. Rosales- Corral S et al., Orally administered melatonin reduces oxidative stress and proinflammatory cytokines induced by amyloid- $\beta$ peptide in rat brain: a comparative, in vivo study versus vitamin $\mathrm{C}$ and $\mathrm{E}$. Journal of pineal research. 2003; 35(2):80-84.

52. Huang J, May JM. Ascorbic acid protects SH-SY5Y neuroblastoma cells from apoptosis and death induced by $\beta$-amyloid. Brain research. 2006; 1097(1):52-58.

53. Dhingra D, Parle M, Kulkarni S. Comparative brain cholinesterase-inhibiting activity of Glycyrrhiza glabra, Myristica fragrans, ascorbic acid, and metrifonate in mice. Journal of medicinal food. 2006; 9(2):281-283.

54. Nagayama $\mathrm{H}$ et al., The effect of ascorbic acid on the pharmacokinetics of levodopa in elderly patients with Parkinson disease. Clinical neuropharmacology. 2004; 27(6):270-273.

55. Wagner G, Carelli RM, Jarvis M. Ascorbic acid reduces the dopamine depletion induced by methamphetamine and the 1-methyl-4-phenyl pyridinium ion. Neuropharmacology. 1986; 25(5):559-561.

56. Rebec GV et al., Ascorbate treatment attenuates the Huntington behavioral phenotype in mice. Neuroreport. 2003; 14(9):1263-1265.

57. Cavalier $\mathrm{L}$ et al., Ataxia with isolated vitamin $\mathrm{E}$ deficiency: heterogeneity of mutations and phenotypic variability in a large number of families. The American Journal of Human Genetics. 1998; 62(2):301-310.

58. Ouahchi $\mathrm{K}$ et al., Ataxia with isolated vitamin $\mathrm{E}$ deficiency is caused by mutations in the $\alpha$-tocopherol transfer protein. Nature genetics, 1995; 9(2):141-145.

59. Ulatowski LM, Manor D. Vitamin E and neurodegeneration. Neurobiology of disease. 2015; 84:78-83.

60. Muller D, Harries J, Lloyd J. The relative importance of the factors involved in the absorption of vitamin $\mathrm{E}$ in children. Gut. 1974; 15(12):966-971.

61. Bye A et al., Symptomatic vitamin E deficiency in cystic fibrosis. Archives of disease in childhood. 1985; 60(2):162-164

62. Willison $\mathrm{H}$ et al., A study of the relationship between neurological function and serum vitamin $E$ concentrations in patients with cystic fibrosis. Journal of Neurology, Neurosurgery \& Psychiatry, 1985; 48(11):1097-1102.

63. Sitrin MD et al., Vitamin E deficiency and neurologic disease in adults with cystic fibrosis. Annals of internal medicine. 1987; 107(1):51-54.

64. Tappel A. Vitamin E as the biological lipid antioxidant, in Vitamins \& Hormones. Elsevier, 1962, 493-510.

65. Burton G, Joyce A. Ingold, KU. Arch. Biochem. Biophys. $1983 ; 221: 281-290$.

66. Traber MG, Atkinson J. Vitamin E, antioxidant and nothing more. Free radical biology and medicine. 2007; 43(1):4-15.

67. Fahrenholtz SR et al., On the quenching of singlet oxygen by $\alpha$-tocopherol. Photochemistry and Photobiology. 1974; 20(6):505-509.

68. Sies H, Stahl W, Sundquist AR. Antioxidant Functions of Vitamins: Vitamins E and C, Beta- Carotene, and Other
Carotenoids a. Annals of the New York Academy of Sciences. 1992; 669(1):7-20.

69. Behl C. Vitamin E protects neurons against oxidative cell death in vitro more effectively than $17-\beta$ estradiol and induces the activity of the transcription factor $N F-\kappa B$. Journal of neural transmission. 2000; 107(4):393-407.

70. Behl C et al., Vitamin E protects nerve cells from amyloid $\beta$ protein toxicity. Biochemical and biophysical research communications. 1992; 186(2):944-950.

71. Sano $\mathrm{M}$ et al., A controlled trial of selegiline, alphatocopherol, or both as treatment for Alzheimer's disease. New England Journal of Medicine, 1997; 336(17):12161222.

72. Prasad KN et al., Multiple antioxidants in the prevention and treatment of Alzheimer disease: analysis of biologic rationale. Clinical neuropharmacology. 2000; 23(1):2-13.

73. Saito $\mathrm{Y}$ et al., Cytoprotective effects of vitamin $\mathrm{E}$ homologues against glutamate-induced cell death in immature primary cortical neuron cultures: Tocopherols and tocotrienols exert similar effects by antioxidant function. Free Radical Biology and Medicine. 2010; 49(10):1542-1549.

74. Magalhaes $\mathrm{J}$ et al., Effect of a high-altitude expedition to a Himalayan peak (Pumori, 7,161 m) on plasma and erythrocyte antioxidant profile. European journal of applied physiology. 2005; 93(5-6):726-732.

75. Annweiler $\mathrm{C}$ et al., Vitamin D and ageing: neurological issues. Neuropsychobiology. 2010; 62(3):139-150.

76. Norman AW. The history of the discovery of vitamin D and its daughter steroid hormone. Annals of Nutrition and Metabolism. 2012; 61(3):199-206.

77. Holick MF. Vitamin D deficiency. New England Journal of Medicine. 2007; 357(3):266-281.

78. Brown $\mathrm{J}$ et al., 1, 25-dihydroxyvitamin D3 induces nerve growth factor, promotes neurite outgrowth and inhibits mitosis in embryonic rat hippocampal neurons. Neuroscience letters. 2003; 343(2):139-143.

79. Garcion E et al., New clues about vitamin D functions in the nervous system. Trends in Endocrinology \& Metabolism. 2002; 13(3):100-105.

80. De Viragh PA, Haglid K, Celio M. Parvalbumin increases in the caudate putamen of rats with vitamin $\mathrm{D}$ hypervitaminosis. Proceedings of the National Academy of Sciences. 1989; 86(10):3887-3890.

81. Kalueff AV, Tuohimaa P. Neurosteroid hormone vitamin $\mathrm{D}$ and its utility in clinical nutrition. Current Opinion in Clinical Nutrition \& Metabolic Care. 2007; 10(1):12-19.

82. McGrath J. Hypothesis: is low prenatal vitamin D a riskmodifying factor for schizophrenia? Schizophrenia research. 1999; 40(3):173-177.

83. Mackay-Sim A et al., Schizophrenia, vitamin D, and brain development. International review of neurobiology. 2004; 59:351-380.

84. Özer S et al., Is vitamin D hypothesis for schizophrenia valid? Independent segregation of psychosis in a family with vitamin-D-dependent rickets type IIA. Progress in Neuro-Psychopharmacology and Biological Psychiatry. 2004; 28(2):255-266.

85. Armstrong D et al., Vitamin D deficiency is associated with anxiety and depression in fibromyalgia. Clinical rheumatology. 2007; 26(4):551-554.

86. Hoogendijk WJ et al., Depression is associated with decreased 25-hydroxyvitamin $\mathrm{D}$ and increased parathyroid hormone levels in older adults. Archives of 
general psychiatry. 2008; 65(5):508-512.

87. Alam W, Hollis B. Vitamin D vs broad spectrum phototherapy in the treatment of seasonal affective disorder. The journal of nutrition, health \& aging. 1999; 3(1):5-7.

88. Pack A. Bone health in people with epilepsy: is it impaired and what are the risk factors? Seizure. 2008; 17(2):181-186.

89. Gonzalez-Burgos E, Gomez-Serranillos M. Terpene compounds in nature: a review of their potential antioxidant activity. Current medicinal chemistry. 2012; 19(31):5319-5341.

90. Wojtunik KA, Ciesla LM, Waksmundzka-Hajnos M. Model studies on the antioxidant activity of common terpenoid constituents of essential oils by means of the 2 , 2-diphenyl-1-picrylhydrazyl method. Journal of agricultural and food chemistry. 2014; 62(37):9088-9094.

91. Di Mascio P, Kaiser S, Sies H. Lycopene as the most efficient biological carotenoid singlet oxygen quencher. Archives of biochemistry and biophysics, 1989; 274(2):532-538.

92. Rao A, Agarwal S. Effect of diet and smoking on serum lycopene and lipid peroxidation. Nutrition research. 1998; 18(4):713-721.

93. Sinclair AJ et al., Altered plasma antioxidant status in subjects with Alzheimer's disease and vascular dementia. International journal of geriatric psychiatry. 1998; 13(12):840-845.

94. Burton GW, Ingold K. Beta-carotene: an unusual type of lipid antioxidant. Science. 1984; 224(4649):569-573.

95. Packer $\mathrm{J}$ et al., Free radicals and singlet oxygen scavengers: reaction of a peroxy-radical with $\beta$-carotene, diphenyl furan and 1, 4-diazobicyclo $(2,2,2)$-octane. Biochemical and biophysical research communications, 1981; 98(4):901-906.

96. Kanhere $\mathrm{R}$ et al., Neuroprotective and antioxidant potential of terpenoid fraction from Hygrophila auriculata against transient global cerebral ischemia in rats. Pharmaceutical biology. 2013; 51(2):181-189.

97. Weber G. Final common pathways in neurodegenerative diseases: regulatory role of the glutathione cycle. Neuroscience \& Biobehavioral Reviews. 1999; 23(8):1079-1086.

98. Cooper AJ. Glutathione in the brain: disorders of glutathione metabolism. The molecular and genetic basis of neurological disease, 1997, 1245-1245.

99. Rathore P et al., Curcuma oil: reduces early accumulation of oxidative product and is anti-apoptogenic in transient focal ischemia in rat brain. Neurochemical research. 2008; 33(9):1672-1682.

100.Walk AM et al., From neuro-pigments to neural efficiency: The relationship between retinal carotenoids and behavioral and neuroelectric indices of cognitive control in childhood. International Journal of Psychophysiology. 2017; 118:1-8.

101.Pappolla $\mathrm{M}$ et al., An assessment of the antioxidant and the antiamyloidogenic properties of melatonin: implications for Alzheimer's disease. Journal of neural transmission. 2000; 107(2):203-231.

102.Poeggeler B et al., Melatonin reverses the profibrillogenic activity of apolipoprotein E4 on the Alzheimer amyloid A $\beta$ peptide. Biochemistry. 2001; 40(49):14995-15001.

103.Clapp-Lilly KL et al., Melatonin acts as antioxidant and pro-oxidant in an organotypic slice culture model of Alzheimer's disease. Neuroreport, 2001; 12(6):12771280.

104.De Feudis F, Drieu K. Ginkgo biloba extract (EGb 761) and CNS functions basic studies and clinical applications. Current drug targets. 2000; 1(1):25-58.

105. Oken BS, Storzbach DM, Kaye JA. The efficacy of Ginkgo biloba on cognitive function in Alzheimer disease. Archives of neurology. 1998; 55(11):1409-1415.

106.Ross GW, Petrovitch H. Current evidence for neuroprotective effects of nicotine and caffeine against Parkinson's disease. Drugs \& aging. 2001; 18(11):797806.

107.Tüchsen F, Jensen AA. Agricultural work and the risk of Parkinson's disease in Denmark, Scandinavian journal of work, environment \& health, 2000, 359-362, 1981-1993..

108.Lee Y et al., Inhibition of Oxidative Neurotoxicity and Scopolamine-Induced Memory Impairment by $\gamma$ Mangostin: In vitro and In vivo Evidence. Oxidative medicine and cellular longevity, 2019.

109. Alonso D, Castro A, Martinez A. Marine compounds for the therapeutic treatment of neurological disorders. Expert Opinion on Therapeutic Patents. 2005; 15(10):1377-1386.

110.Frenz JL, Kohl AC, Kerr RG. Marine natural products as therapeutic agents: Part 2. Expert Opinion on Therapeutic Patents. 2004; 14(1):17-33.

111.Levites $\mathrm{Y}$ et al., Green tea polyphenol (-)epigallocatechin- 3- gallate prevents N- methyl- 4phenyl- 1, 2, 3, 6- tetrahydropyridine- induced dopaminergic neurodegeneration. Journal of neurochemistry. 2001; 78(5):1073-1082.

112. Wood T, Nance E. Disease-directed engineering for physiology-driven treatment interventions in neurological disorders. APL bioengineering. 2019; 3(4):040901.

113.Esposito E et al., A review of specific dietary antioxidants and the effects on biochemical mechanisms related to neurodegenerative processes. Neurobiology of aging. 2002; 23(5):719-735.

114.Prasad KN et al., Multiple antioxidants in the prevention and treatment of neurodegenerative disease: analysis of biologic rationale. Current opinion in neurology. 1999; 12(6):761-770. 